\title{
Psychiatry at undergraduate level in India: What is needed?
}

\author{
Anjana Rao Kavoor, Sayantanava Mitra ${ }^{1}$ \\ Department of Psychiatry, Institute of Mental Health and Hospital, '1Department of Psychiatry, Sarojini Naidu Medical College, Agra, \\ Uttar Pradesh, India
}

\section{ABSTRACT}

Present day health-care philosophy strongly favors an increased attention to mental health related issues. However, the lack of an adequate number of trained specialists in India in this field makes it imperative that the burden is shared by general practitioners at large. But our current medical education system may not be equipped enough to prepare them for the task.

Key words: Undergraduate, Psychiatry, India

Psychiatry as a specialty remains neglected at undergraduate level medical curriculum in India. This is in spite of a ubiquitous emphasis on part of WHO toward inclusion of mental health in defining overall well-being of mankind. Over recent years, the burden of psychiatric illnesses has steadily increased throughout the world ${ }^{[1]}$ and a need for well-trained professionals to tackle these issues at present is impossible to miss. Having remained shrouded for ages in an awe-inspiring and incomprehensible veil of magico-religious etiology, only with advent of $21^{\text {st }}$ century has psychiatry broken the slumber and tried to shake off the skepticism that it had accumulated over centuries. ${ }^{[2]}$ Now is perhaps the best time to look forward and prepare a workforce that would help achieve a comprehensive "health" for the society.

A proper emphasis on training and education in mental disorders is of paramount importance in every healthcare system, more so when it is the second most populous country on this planet. With 509 total post-graduate (PG) seats, psychiatry represents merely $2.2 \%$ of all the broad-specialties India has to offer ${ }^{[3]}$ in medical sciences.

\begin{tabular}{|l|l|}
\hline \multicolumn{2}{|c|}{ Access this article online } \\
\hline Quick Response Code: & Website: \\
\hline & www.ruralneuropractice.com \\
\cline { 2 - 3 } & \\
\hline & \\
\hline
\end{tabular}

Thus, we produce roughly about 1 psychiatrist per 2.5-million population per year. Considering the prevalence data of various psychiatric disorders, this is but a drop in the ocean. This exerts undue pressure on the psychiatrists, who are themselves plagued by a multitude of problems, both at academic and professional levels; ${ }^{[2,4]}$ and therefore it becomes imperative that a large number of these patients be served by non-specialists.

But are we ready for that yet? An undergraduate (UG) medical student in India hardly has a brush with psychiatry during the five and a half years spent at medical school. Considered as one of the least important subjects during this period, the lectures and ward postings in psychiatry are well engulfed by more demanding and authoritative subjects of medicine, surgery and obstetrics. ${ }^{[5]}$ Psychiatry ends up remaining a small part of general medicine course, and the student passes his final professional examination by memorizing a few short notes, for only this much is required of them. According to current medical interns, psychiatry ward remains obscure and a place to relax after the hectic postings of labor rooms and emergency/casualties. More disturbing is the lack of even basic teaching infrastructure in psychiatry in many undergraduate medical colleges, and of teachers in psychiatry who are "inspiring" enough. ${ }^{[5]}$ The end result, in our experience, is a large number of trained medical graduates lacking grossly in psychiatric interviewing skills, their abilities to empathize and understand psychopathology. To complete the circle, perhaps driven by this lack of clarity and exposure, only

Address for correspondence:

Dr. Sayantanava Mitra, Department of Psychiatry, Sarojini Naidu Medical College, Agra, Uttar Pradesh, India. E-mail: sayantanava@gmail.com 
a few of them become interested and take up psychiatry for their post-graduation. Hence, this vicious cycle perpetuates and continues to haunt this specialty.

How do we solve this problem? How do we ensure that psychiatry receives its due emphasis in UG curriculum? External mandates and enforcements are likely to prove insufficient, and therefore the change has to come from within. We need to create conditions conducive enough for this to happen. Given the pace at which this field is advancing, it is sure to capture young imaginations. What the students need is some stimulation and an adequate level of exposure, to make them feel interested and become engrossed. A comprehensive yet brief course curriculum, enthusiastic faculty, and implementation of quality evaluations could all improve student engagement and promote psychiatry to where it deserves to be. Perhaps these hold the key to current mental health care problems in India.

\section{References}

1. Murray CJ, Lopez AD. Global burden of disease and injury series. In: Murray CJ, Lopez AD, editors. The Global Burden of Disease: A Comprehensive Assessment of Mortality and Disability from Diseases, Injuries and Risk Factors in 1990 is and Projected to 2020. Vol. 1. Cambridge, MA: Harvard School of Public Health on behalf of the World Health Organization and the World Bank, Harvard University Press; 1996.

2. Mitra S, Kavoor AR. Psychiatry in $21^{\text {st }}$ century: The road ahead. J Neurosci Rural Pract 2014;5:426-7.

3. Ananthakrishnan N. Distribution of postgraduate medical seats in different disciplines: Is there rationality in decision-making? Natl Med J India 2011;24:365-7.

4. Osvath P. Psychiatry in $21^{\text {st }}$ century: The long and hard road ahead. J Neurosci Rural Pract 2015;6:1.

5. Reddy IR. Undergraduate psychiatry education: Present scenario in India. Indian J Psychiatry 2007;49:157-8.

How to cite this article: Kavoor AR, Mitra S. Psychiatry at undergraduate level in India: What is needed?. J Neurosci Rural Pract 2015;6:449-50.

Source of Support: Nil. Conflict of Interest: None declared. 